\title{
REDEN VON \\ EMIL DU BOIS-REYMOND
}

IN ZWEI BÄNDEN

ZWEITE VERVOLLSTÄNDIGTE AUFLAGE

MIT EINER GEDÄCHTNISREDE VON

JULIUS ROSENTHAL

HERAUSOEGEBEN VON

ESTELLE DU BOIS-REYMOND

ZWEITER BAND

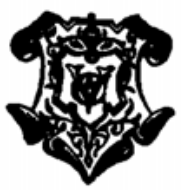

VERLAG VON VEIT \& COMP., LEIPZIG 1912 
Das Recht der Herausgabe von Ubersetzungen vorbehalten. 